JACKSON, R M. (1958). J. gen. Microbiol. 18, 248-258

\title{
An Investigation of Fungistasis in Nigerian Soils
}

\author{
By R. M. JACKSON \\ Faculty of Agriculture, University College, Ibadan, Nigeria*
}

\begin{abstract}
SUMMARY: The presence of a fungistatic factor in Nigerian soils was demonstrated by the use of a technique in which disks of agar were placed on filter-paper in contact with moist unsterile soil and inoculated with fungal spores. After incubation the disks were examined and the percentage of germinated spores recorded. Inhibition of spore germination was not caused by autoclaved soil, nor when $0.5 \%(\mathrm{w} / \mathrm{v})$ glucose was present in the agar. The presence or absence and the type of vegetation had little effect on the fungistatic power of the soil. In two profiles examined, the property of fungistasis was confined, approximately, to the upper $40 \mathrm{~cm}$. of the soil. Of nineteen species of fungi tested by the agar disk method, the germination of eleven was significantly inhibited, of seven unaffected and of one stimulated. The data obtained suggest that the phenomenon described in Nigerian soils is similar to that reported from other parts of the world.
\end{abstract}

Several workers have reported the occurrence of factors toxic or inhibitory to the growth of soil fungi and bacteria in a variety of natural soils in different countries. In Britain, Dobbs \& Hinson (1953) reported complete inhibition of spore germination of Penicillium frequentans by the following soils, which came from different localities in England and Wales: five forest soils, five grassland soils including acid and calcareous types, three garden soils of differing fertility levels and three waterlogged soils. The work of Neilson-Jones (1941), Brian, Hemming \& McGowan (1945) and Jefferys \& Hemming (1953) was concerned with an acid heath soil from Wareham Heath in Dorset, which supported poor tree growth and was found to be toxic to fungi and bacteria. Neilson-Jones also detected some toxicity in 'normal' heath soil from Oxshott in Surrey. Hessayon (1953) found a factor inhibitory to Trichothecium roseum to be present in larger quantities in a clay than in a sandy soil. Park (1955, 1956) used a light garden loam in his studies in which he observed the lysis of fungal spores in contact with this soil. Winter $(1940,1955)$, working in Germany, obtained soil extracts inhibitory to Ophiobolus graminis, and extracts of pine litter and lysimeter water which were both shown to contain antibiotic substances. The leaf litter of several different tree species in Sweden has been found to exert an antibiotic effect on mycorrhizal fungi (Melin, 1946); while in France, Pochon \& Barjac (1952) demonstrated that aqueous extracts of peat soils have a strong inhibitory effect on some bacteria, in particular Azotobacter chroococcum.

One of the earliest reports of toxic material in soils is that of Greig-Smith (1911), who found that Australian soils would yield aqueous extracts toxic to Bacillus prodigiosus (Serratia marcescens) and to a lesser extent to other bacteria. In America evidence has been obtained for the presence of inhibitory

* Present address : Soil Microbiology Department, Rothamsted Experimental Station, Harpenden, Hertfordshire. 
material in subsurface soils (Newman $\&$ Norman, 1943) and Canadian workers (Simmonds, Sallans \& Ledingham, 1950; Chinn, 1953) have detected fungistatic activity towards Helminthosporium sativum and some other fungi in several soils tested. Stover (1955), in a study of Fusarium oxysporum f. cubense in Honduras, observed that the spores of this fungus germinated poorly or not at all in unsterile soil, unless glucose, plant sap or other nutrients were added; this appears to be the only report of the inhibitory action of soil from the tropics.

The present work was undertaken to determine whether or not soil fungistasis, similar to that reported from other countries, occurs in the southern part of Nigeria, a region which lies within the Humid Tropics and has an annual mean temperature between $75^{\circ}$ and $85^{\circ} \mathrm{F} .\left(c .20-30^{\circ} \mathrm{C}\right.$.) and an annual rainfall of 40-80 in. When fungistasis was observed, some of the aspects of its distribution and properties were studied.

\section{METHODS}

Organisms. The following fungi were used: Mucor fragilis Bain., Commonwealth Mycological Institute (IMI) 54600; Cunninghamella elegans Lendner, IMI 54404; Ustilago zeae (Beckm.) Unger; Puccinia polysora Underw.; Aspergillus niger van Tiegh., IMI 54399; Aspergillus violaceo-fuscus Gasp., IMI 54401; Aspergillus fischeri Wehm., IMI 54403; Penicillium citrinum Thom, IMI 54218; Penicillium terrestre Jensen series, IMI 54216; Penicillium verruculosum Peyronel, IMI 54220; Penicillium avellaneum Thom \& Turesson, IMI 54225; Paecilomyces varioti Bain., IMI 54401; Gliocladium deliquescens Sopp series, IMI 54219; Myrothecium verrucaria Ditmar ex Fries, IMI 54694; Fusarium solani sensu Snyder \& Hansen, IMI 54696; Fusarium equiseti (Corda) Sacc., IMI 54697; Cladosporium cladosporioides (Fres.) de Vries, IMI 54705; Helminthosporium ravenellii Curt.

These fungi, with the exceptions of Ustilago zeae, Puccinia polysora and Helminthosporium ravenellii, were all isolated from soil at Ibadan, and were identified or their identities confirmed by the Commonwealth Mycological Institute, whose acquisition numbers are given. The material of the plant pathogenic fungi was freshly collected at Ibadan.

Media. Distilled water agar (2.0\%): $2 \cdot 0 \%(\mathrm{w} / \mathrm{v})$ Difco 'Bacto-Agar' in glass-distilled water, autoclaved at $120^{\circ}$ for $20 \mathrm{~min}$. Czapek agar: $\mathrm{NaNO}_{3}, \mathbf{2 \cdot 0} \mathrm{g}$.; $\mathrm{K}_{2} \mathrm{HPO}_{4}, 1.0$ g.; $\mathrm{MgSO}_{4} .7 \mathrm{H}_{2} \mathrm{O}, 0.5 \mathrm{~g}$.; $\mathrm{KCl}, 0.5$ g.; $\mathrm{FeSO}_{4}, 0.1 \mathrm{~g}$; sucrose $30.0 \mathrm{~g}$; ; agar $15.0 \mathrm{~g}$.; tap water to $1000.0 \mathrm{ml}$.; autoclaved at $120^{\circ}$ for $20 \mathrm{~min}$. Lactophenol (Amann): phenol, 20 g.; lactic acid, 20 g.; glycerol, 40 g.; water, $20 \mathrm{~g}$.

The agar disk method for assessing soil fungistasis

When a study of soil fungistasis was started, it was thought desirable to devise a simple method for assessing the fungistatic activity of soils or for comparing the sensitivity of different fungi to fungistasis, which would yield quantitative data suitable for statistical analysis. Techniques for detecting the presence of inhibitory factors in soil dependent upon diffusion from soil into 
agar have been used by Neilson-Jones (1941), Hessayon (1953), Jefferys \& Hemming (1953) and Witkamp \& Starkey (1956), while Dobbs \& Hinson (1953) detected fungistatic material diffusing from soil through cellulose film. The buried-slide technique of Chinn (1953), in which a glass slide coated with a spore suspension in agar is buried in the soil and later recovered for examination, can yield qualitative and quantitative data on the effects of inhibitory soil factors on spores. This technique provides a rather more sensitive test for fungistasis than the agar disk method to be described, but was found less convenient to handle and the results more difficult to record quantitatively in routine tests. For special studies (Jackson, 1957) Chinn's technique has been found invaluable. Preliminary experiments, in which cellulose film squares were placed in contact with the surface of moist soil and inoculated on the upper surface with fungal spores, showed that although such squares could be readily removed to a microscope slide for examination, unsatisfactory results were obtained owing to uneven contact between the soil and the film and also to partial drying of the cellulose. As an alternative to cellulose film, the possibility of using agar disks placed in contact with the soil was examined and the following method developed.

Preparation of soil samples. Composite samples were passed through a $2 \mathrm{~mm}$. sieve, either immediately after collecting or after air-drying for $12 \mathrm{hr}$., and thoroughly mixed before testing. Forty to $60 \mathrm{~g}$. of soil were placed in a clean $85 \mathrm{~mm}$. Petri dish and brought to approximately $60 \%$ of water-holding capacity by the addition of distilled water.

Agar disks. These were prepared by pouring $9 \mathrm{ml}$. of melted $2 \%(\mathrm{w} / \mathrm{v})$ distilledwater agar into a selected flat-bottomed $85 \mathrm{~mm}$. Petri dish standing on a level surface, giving a layer of agar just under $1.5 \mathrm{~mm}$. in thickness. The disks were cut from the agar with a flamed $7.5 \mathrm{~mm}$. diameter cork-borer and removed on the tip of a flamed scalpel.

Test organism. The organism used was a strain of Penicillium citrinum, isolated from soil at Ibadan, and was used in all experiments with the exception of those in which the sensitivities of different fungi to soil fungistasis were being examined. $\boldsymbol{P}$. citrinum was chosen on account of the initial high percentage germination of its conidia on water agar, its sensitivity to soil fungistasis and the rapidity with which it produced heavy crops of spores on nutrient media. Spore suspensions were prepared from young, heavily sporulating cultures on Czapek agar.

Procedure. In the first tests the agar disks were placed in direct contact with the soil. It was found that three disadvantages were associated with this procedure, namely, uneven contact between the agar and the soil, adhesion of soil particles to the agar on removing the disk from the soil and the growth of fungal hyphae from the soil into the agar. The first of these difficulties was decreased and the second and third of them eliminated by interposing one thickness of Whatman's no. 1 filter-paper between agar disk and soil, with only a slight decrease in the sensitivity of the test. For each test, four $1 \mathrm{~cm}$. squares of filterpaper are placed on the surface of the soil in a Petri dish and an agar disk placed on each of the squares. Either immediately, or after 1-4 hr. of incuba- 
tion to allow diffusion of inhibitory substances from soil into agar disk, the surface of each disk was inoculated with a drop of a spore suspension in distilled water on the end of a glass rod. Provided that control and treated disks were inoculated with samples of the same spore suspension, standardization of the suspension was not necessary. Controls were similarly prepared, but the agar disks were placed on filter-papers saturated with distilled water in dishes containing no soil. After inoculation, the Petri dish with lid replaced was incubated at room temperature $\left(20-27^{\circ}\right.$ in Ibadan) or at $25^{\circ}$ in an incubator for the minimum period required to obtain good germination of the spores on the control disks, which was $16 \mathrm{hr}$. with Penicillium citrinum.

After incubation the agar disks were removed to microscope slides and covered with a drop of lactophenol and a coverslip. Germinated and ungerminated spores in each of four random microscope fields on each agar disk were counted, the magnification used depending on the size and density of distribution of the spores. Spores were recorded as having germinated when they had produced a germ tube of one spore diameter or more in length. Results are expressed as the $\%$ of the total number of spores that had germinated, and, after angular transformation, may be submitted to analysis by Student's $t$ test or analysis of variance.

\section{RESULTS}

Demonstration of soil fungistasis and the effect on this of autoclaving the soil

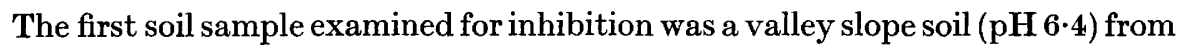
the University College site, Ibadan, which had for the $\mathbf{3}$ years before sampling carried a stand of young teak trees (Tectona grandis). The sample was a composite one collected from the upper $8 \mathrm{~cm}$. of soil and air-dried before bringing to $60 \%$ water-holding capacity and testing (air-drying for short periods was found to have no appreciable effect on soil fungistasis). After moistening, one part of the sample was tested without further treatment, while another part was autoclaved at $120^{\circ}$ for $30 \mathrm{~min}$. before testing. The agar disk method was used with Penicillium citrinum as the test organism. The results of the spore germination counts from this experiment are presented in Table 1, together with the analysis of variance table. The results of further experiments in which the agar disk method was used are expressed as mean $\%$ and mean transformed $\%$ germinations, with an indication of the significance of the means. While the untreated soils tested in this experiment almost completely inhibited germination of the test organism, autoclaving removed this effect and resulted in a degree of germination not significantly different from that of the control.

\section{The effect of glucose on the inhibitory factor}

Dobbs \& Hinson (1953) reported that as little as $0 \cdot 1 \%(\mathrm{w} / \mathrm{v})$ glucose + inorganic salts added to their soil resulted in the disappearance of the fungistatic effect. In the present work a test was carried out at the same time and with part of the same soil sample as was used in the previous experiment, to determine the effect of adding glucose to the agar used in preparing the agar disks. While the concentration of glucose was likely to remain substantially 
constant in the agar disks during a test, a small concentration of glucose added to unsterile soil might be expected to start decreasing appreciably within a few hours of addition. In this experiment $0.5 \%(\mathrm{w} / \mathrm{v})$ glucose was added to the agar in the treated and control disks, and Penicillium citrinum was used as the test organism. It was found that no significant inhibition of spore germination occurred on agar disks containing $0 \cdot 5 \%(\mathrm{w} / \mathrm{v})$ glucose placed over the soil.

\section{Table 1. The germination of Penicillium citrinum conidia on agar disks over filter-paper, untreated soil and autoclaved soil}

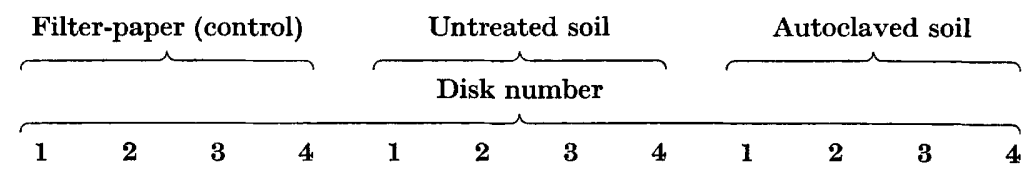

Field

1

3

4
Germinated Ungerminated

Germinated Ungerminated

Germinated Ungerminated

Germinated

Ungerminated

$\%$ germinated

Angular transformation

Source of variance Between columns Within columns

Count (germinated and ungerminated conidia)/4 microscope fields

\begin{tabular}{|c|c|c|c|c|c|c|c|c|c|c|c|}
\hline 68 & 98 & 93 & 98 & 2 & 1 & 0 & 3 & 32 & 88 & 54 & 71 \\
\hline 17 & 21 & 13 & 35 & 116 & 101 & 53 & 225 & 7 & 31 & 9 & 47 \\
\hline 50 & 77 & 63 & 82 & 3 & $\mathbf{0}$ & 0 & 1 & 62 & 99 & 62 & 98 \\
\hline 15 & 20 & 4 & 16 & 59 & 94 & 46 & 112 & $\mathbf{5}$ & 23 & 10 & 39 \\
\hline 55 & 68 & 76 & 90 & 2 & 1 & $\mathbf{0}$ & $\mathbf{1}$ & 98 & 59 & 61 & 94 \\
\hline 9 & 8 & 14 & 25 & 80 & 21 & 143 & 103 & 10 & 14 & 22 & 47 \\
\hline 61 & 59 & 114 & 80 & $\mathbf{3}$ & 0 & $\mathbf{0}$ & 1 & 67 & 75 & 61 & 72 \\
\hline 11 & 12 & 22 & 15 & 93 & 71 & 125 & 131 & 10 & 22 & 17 & $\mathbf{3 7}$ \\
\hline $81 \cdot 8$ & $83 \cdot 2$ & $86 \cdot 7$ & $79 \cdot 4$ & $2 \cdot 8$ & $0 \cdot 7$ & $\mathbf{0}$ & $1 \cdot 0$ & $89 \cdot 0$ & $78 \cdot 1$ & $80 \cdot 4$ & $66 \cdot 3$ \\
\hline $64 \cdot 9$ & $65 \cdot 6$ & 68.9 & $62 \cdot 7$ & $10 \cdot 0$ & $5 \cdot 7$ & 0 & $5 \cdot 7$ & $70 \cdot 6$ & $62 \cdot 0$ & $63 \cdot 4$ & $54 \cdot 3$ \\
\hline & \multicolumn{3}{|c|}{ Mean $65 \cdot 5^{*}$} & & \multicolumn{2}{|c|}{ Mean 5.3* } & & & \multicolumn{2}{|c|}{ Mean $62 \cdot \mathbf{6}^{*}$} & \\
\hline
\end{tabular}

Analysis of variance

$\begin{array}{ccc}\text { Sums of squares } & \text { Degrees of freedom } & \text { Mean squares } \\ 9205 \cdot 9 & 2 & \mathbf{4 6 0 2 \cdot 9} \\ \mathbf{2 0 4 \cdot 2} & 9 & \mathbf{2 2 \cdot 7}\end{array}$

* Significant difference between mean s for $P=0.05$ is 7.7 .

\section{Fungistatic nature of the inhibition}

The very poor germination of Penicillium citrinum spores over untreated soil after $16 \mathrm{hr}$. as compared with excellent germination in the absence of soil might have been due either to a slowing in the rate of germination or to complete prevention of the process in most of the spores. In the latter case the spores might have lost their capacity for germination and have become nonviable, or have retained viability, being able to germinate when removed from the influence of the soil or affected by a stimulatory substance. The possibility that the soil delayed rather than prevented germination was examined by setting up an experiment with the same soil and organism as used in the previous tests, but using sufficient agar disks to allow for the removal of four every $24 \mathrm{hr}$. over a period of 1 week, so that any increase in germination during that period could be observed. Observations were not recorded after the fifth day as the growth of fungal and bacterial contaminants on the agar disks made further accurate counts impossible. The results recorded in Table 2 show that 
by the end of 5 days no significant increase in \% germination had occurred. It was observed in this experiment, as in others, that the small \% of spores which did germinate in the presence of the soil factor developed at a slower rate than in the absence of soil.

Table 2. The effect on the germination of Penicillium citrinum conidia of prolonging incubation over soil

$\begin{array}{ccc}\begin{array}{c}\text { Duration of } \\ \text { incubation } \\ \text { (hr.) }\end{array} & \begin{array}{c}\text { Mean } \\ \text { germination } \\ (\%)\end{array} & \begin{array}{c}\text { Mean of transformed } \\ \text { \% germination }\end{array} \\ 16 & 0 \cdot 8 & 4 \cdot 9 \\ 40 & 2 \cdot 4 & 7 \cdot 0 \\ 64 & 7 \cdot 7 & 13 \cdot 2 \\ 88 & 1 \cdot 3 & 4 \cdot 9 \\ 112 & 4 \cdot 2 & 10 \cdot 4\end{array}$

Differences between means not significant at $P=0 \cdot 05$.

To determine whether or not the inhibitory soil factor is toxic, four inoculated disks which had been in contact with soil for $16 \mathrm{hr}$. were removed for microscopic examination and subsequently placed on filter-paper moistened with $1.0 \%(\mathrm{w} / \mathrm{v})$ solution of glucose in distilled water and incubated for a further $24 \mathrm{hr}$. before re-examination. The \% germination of the spores on these disks reached a value near that of those on the control disks which had not been in contact with the soil. The results of this experiment clearly demonstrate that, at least for Penicillium citrinum and with a limited period of exposure under the conditions of the experiment, the soil inhibitory factor had no permanent effect on the germinative capacity of the spores and may therefore be defined as a fungistatic rather than fungicidal.

Table 3. The effect on the germination of Penicillium citrinum conidia of transferring inoculated disks from soil to glucose-moistened filter-paper

\begin{tabular}{|c|c|c|}
\hline Treatment & $\begin{array}{c}\text { Mean } \\
\text { germination } \\
(\%)\end{array}$ & $\begin{array}{l}\text { Mean of transformed } \\
\% \text { germination }\end{array}$ \\
\hline $16 \mathrm{hr}$. over soil & $1 \cdot 7$ & $7 \cdot 4 *$ \\
\hline $\begin{array}{l}16 \mathrm{hr} \text {. over soil }+24 \mathrm{hr} \text {. } \\
\text { over filter-paper }\end{array}$ & $70 \cdot 3$ & $57 \cdot 2$ \\
\hline $16 \mathrm{hr}$. over filter-paper & $72 \cdot 5$ & $58 \cdot 4$ \\
\hline
\end{tabular}

* Significant difference between means for $P=0.05$ is $26 \cdot 2$.

The occurrence of inhibition of fungal growth in different Nigerian soils

In addition to samples from the University College site at Ibadan in the Western Region of Nigeria, some soils from other parts of Nigeria were examined for fungistasis. Samples were collected from the following localities:

(1 and 2) Between Ilorin and Bode Sabu, Ilorin Province, Northern Region; well-developed Guinea Savannah (Encephalartos barteri belt), uncultivated for a considerable period, mixed grass and scrub vegetation. Annual rainfall c. 49 in. 
(3 and 4) Between Oyo and Iseyin, Oyo Province, Western Region; derived Guinea Savannah, probably cultivated within the last 4 years but at the time of sampling under mixed grass fallow. Annual rainfall c. 46 in.

(5 and 6) Asijere, Oyo Province, Western Region; mixed secondary rain forest, estimated to be more than 20 years old. Annual rainfall $c .48 \mathrm{in}$.

(7) Lagos, Federal Region; mangrove (Rhizophora racemosa) swamp. Annual rainfall c. 72 in.

(8) Between Lagos and Ikorodu, Federal Region, freshwater swamp with mixed vegetation. Annual rainfall c. 72 in.

The samples were all composite ones collected from the upper $10 \mathrm{~cm}$. of the soil. Soil samples nos. 1-6 inclusive may be broadly described as moderately to strongly leached porous sandy clays, low in organic matter except for the forest soil samples ( 5 and 6 ) which contained a considerable quantity of organic matter in the upper $10 \mathrm{~cm}$. Sample no. 7 from a mangrove swamp was a silty clay containing a mass of Rhizophora rootlets, while sample no. 8 from a freshwater swamp was a sandy soil rather rich in organic matter. No $\mathrm{pH}$ measurements were made on these samples. The indicated rainfall figures are necessarily approximate as records are available only from a limited number of stations.

The samples were tested for inhibition by the agar disk method with Penicillium citrinum as test organism. Samples nos. 1-6 inclusive were tested together with one control, while samples 7 and 8 were tested at a later date with a different control. As shown in Table 4, significant inhibition was caused by all the soils tested, although the freshwater swamp soil, which was waterlogged at the time of sampling, produced a smaller effect than the other soils.

Table 4. The effect of different soils on the germination of Penicillium citrinum conidia

$\begin{array}{ccc} & \begin{array}{c}\text { Mean } \\ \text { germination } \\ \text { Soil sample no. }\end{array} & \begin{array}{c}\text { Mean of transformed } \\ \text { \% germination }\end{array} \\ 1 & \mathbf{3}) & 10 \cdot 7 * \\ 2 & 4 \cdot 6 & 12 \cdot 2 \\ 3 & 1 \cdot 4 & 3 \cdot 4 \\ 4 & 8 \cdot 4 & 16 \cdot 5 \\ 5 & 6 \cdot 1 & 14 \cdot 1 \\ 6 & 13 \cdot 0 & 20 \cdot 0 \\ \text { Filter-paper control } & 60 \cdot 3 & 51 \cdot 1\end{array}$

* Significant difference between means for $P=0.05$ is $7 \cdot 2$.

$\begin{array}{ccc}7 & 0 & 0 \\ 8 & 59 \cdot 2 & 50 \cdot 3^{*} \\ \text { Filter-paper control } & \mathbf{8 5 \cdot 8} & 67 \cdot 8 \\ * \text { Significantly different from the control at } P=0 \cdot 01 .\end{array}$

The effect of vegetation on soil fungistasis

The effect of vegetation on the inhibitory activity of similar soils was studied in a series of plots receiving different treatments. The plots were established on an area of the University College farm which had been under secondary bush 
vegetation for at least the last 20 years, during which period it had not been cultivated. The area was cleared of vegetation in October 1952, and laid down to the following plots, each $6 \times 90 \mathrm{ft}$., in August 1953 (during the interval between clearing and laying down the plots the soil was rapidly covered by a ground layer of herbaceous weeds): (1) Bare fallow-regularly weeded to keep the plot as nearly as possible free from vegetation. (2) Regenerating vegetation-plot untreated; natural vegetation allowed to regenerate. (3) Planted with Giant Star Grass (Cynodon plectostachyum). (4) Planted with the leguminous cover-crop, Tropical Kudzu (Pueraria phaseoloides). Composite soil samples were taken from the upper $8 \mathrm{~cm}$. of each plot in July 1955, by which time plots 2-4 were thickly covered by vegetation below which was a welldeveloped layer of organic litter. In addition to the samples from the above plots, one composite sample from another part of the farm, carrying a crop of maize, was included in the test for comparative purposes. The agar disk method was again used with the same test organism.

The results (Table 5) of this experiment indicate that all the soil samples caused a highly significant inhibition of spore germination as compared with the control, the inhibition caused by soil from plots nos. 1 and 3 , and the maize plot being significantly greater than that produced by soil from plot 2 , carrying regenerating vegetation. The soil from plot 1 , which had been exposed to the full effects of leaching and insolation for nearly 2 years, showed the highest degree of inhibition.

Table 5. The germination of Penicillium citrinum conidia over soils which have carried different types of vegetation

$\begin{array}{cccc}\text { Plot no. } & \begin{array}{c}\text { MH } \\ \text { value }\end{array} & \begin{array}{c}\text { germination } \\ (\%)\end{array} & \begin{array}{c}\text { Mean of transformed } \\ \% \text { germination }\end{array} \\ 1 & 6 \cdot 2 & 0 \cdot 3 & 0 \cdot 7 \\ 2 & 6 \cdot 6 & 4 \cdot 3 & 11 \cdot 7 \\ 3 & 6 \cdot 4 & 1 \cdot 5 & 3 \cdot 5 \\ 4 & 6 \cdot 3 & 1 \cdot 6 & 4 \cdot 9 \\ \text { Maize plot } & 6 \cdot 0 & 0 \cdot 4 & 2 \cdot 1 \\ \text { Filter-paper control } & - & \mathbf{7 6 \cdot 8} & 61 \cdot 5 \\ \text { * Significant difference between means for } P=0 \cdot 05 \text { is } \mathbf{7 \cdot 2}\end{array}$

\section{The vertical distribution of soil fungistasis}

The distribution of inhibition in two soil profiles was examined. Profile 1 was a hill-top series soil and carried a mixed secondary vegetation with a welldeveloped herb and scrub layer, while profile 2 was a valley slope soil with a thin grass cover of Sporobolus pyramidalis and Panicum maximum; both soils were on the University College site. Profile 1 was sampled from the exposed face of a freshly dug pit at intervals to a depth of $183 \mathrm{~cm}$., the samples from the second profile being collected with a screw auger to a depth of $91 \mathrm{~cm}$. The samples were tested by the agar disk method with Penicillium citrinum as the test organism. The results are represented graphically in Fig. 1. In both the profiles inhibitory material was present in the samples taken down to $30 \mathrm{~cm}$. 
but not in the next lower samples, which showed a slight but significant, stimulation, which was not present at $91 \mathrm{~cm}$. in the second profile. The $\mathrm{pH}$ values of the samples from profile 1 ranged from $5 \cdot 6$ to $6 \cdot 0$ and of the samples from profile 2 from $5 \cdot 6$ to $6 \cdot 6$.
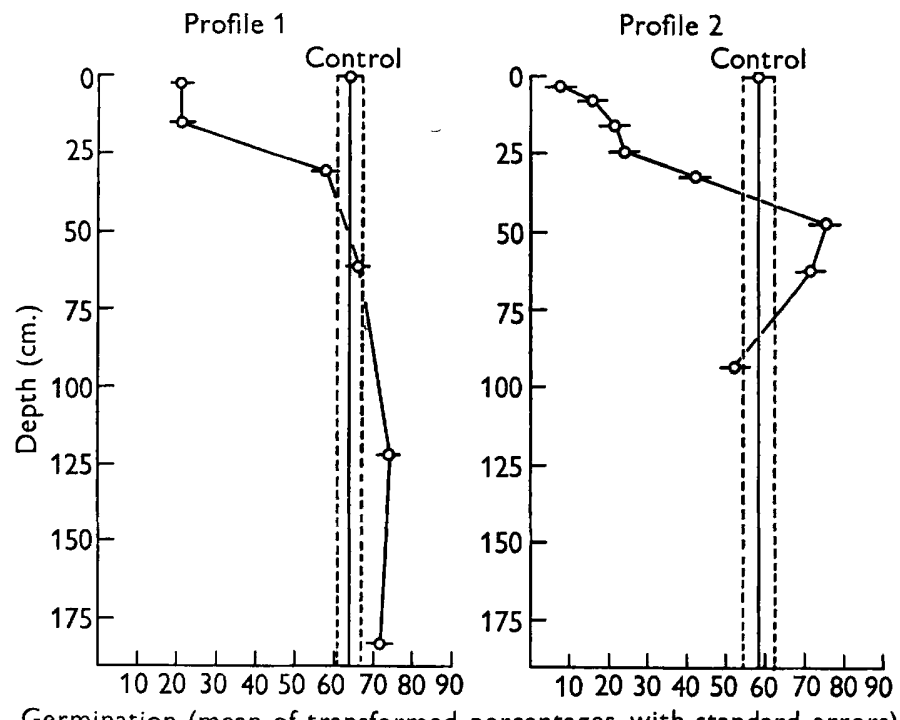

Germination (mean of transformed percentages with standard errors)

Fig. 1. The effect of soil samples taken from different depths in two profiles on the germination of Penicillium citrinum conidia. Germination in the absence of soil is indicated by a vertical line on each graph.

\section{The sensitivity of different fungi to soil fungistasis}

Preliminary results obtained while a suitable test organism for use in the agar disk test was being sought had indicated that there existed considerable differences between the sensitivities of different fungi to the inhibitory effect of soil. Sixteen fungi isolated from local soils and three plant pathogenic fungi were tested for sensitivity to Ibadan soil. All the fungi were tested by the agar disk method against a sample of the same soil as used in the first experiment described, a reference disk inoculated with Penicillium citrinum being included in each soil plate. Conidial suspensions were obtained from Czapek agar-plate cultures incubated for a sufficient period to allow of good sporulation, except in the case of Ustilago zeae, Puccinia polysora and Helminthosporium ravenellii, where brandspores, uredospores and conidia, respectively, were obtained directly from infected plant material. The fungi tested gave results which allow them to be placed in three categories according to whether germination of their spores was significantly (at $P=0.05$ ) inhibited, unaffected, or stimulated, respectively, by soil as compared with spores incubated over moist filter-paper. Inhibited were: Mucor fragilis, Ustilago zeae, Penicillium citrinum, $P$. terrestre, $P$. verruculosum, Aspergillus niger, $A$. violaceofuscus, Gliocladium deliquescens, Trichoderma viride, Cladosporium cladosporioides, Myrothecium verrucaria; unaffected were: Cunninghamella elegans, 
Puccinia polysora, Penicillium avellaneum, Aspergillus fischeri, Paecilomyces varioti, Fusarium solani, Fusarium equiseti; stimulated was: Helminthosporium ravenellii. While a significant inhibition on agar disks over soil may be taken as indicative of a strong inhibition in the soil, lack of inhibition on agar disks cannot be taken as proof of no inhibition in the soil.

\section{DISCUSSION}

The results obtained in the experiments described indicate the common occurrence in soils of south-western Nigeria of inhibitory material effective against certain fungi and similar to (or identical with) that described by workers in other countries. This similarity is suggested by the following features of the inhibition studied in Nigeria: (1) the presence in all soils tested of waterdiffusible material which inhibits the germination of the spores of several different species of fungi; (2) the fungistatic properties of this material; (3) disappearance of the inhibition on autoclaving the soil; (4) counteraction of the effect by glucose. Although it was possible to examine only a limited number of different soils, the fact that all the soils tested showed some degree of fungistatic activity would suggest that the majority of Nigerian soils might be expected to show a similar effect. The rather low activity in a waterlogged, freshwater swamp soil might be accounted for by decreased production of the inhibitory material under partially anaerobic conditions or by some loss of the factor resulting from prolonged leaching.

An interesting feature of the plot experiment was the presence of a strong fungistatic effect in soil from the bare fallow plot after nearly 2 years of subjection to repeated intense insolation and leaching. During this period no additions of organic or inorganic material were made to the plot, so that latterly the activity of micro-organisms might have been expected to have been low. It would appear from these considerations that, if the material is microbial in origin, it must possess a high degree of resistance to leaching and to chemical and biological inactivation in the soil. Inhibition has been reported in surface and subsurface soils down to a depth of $4 \mathrm{ft}$. (Newman \& Norman, 1943; Dobbs \& Hinson, 1953), but in the present study was not found below $30 \mathrm{~cm}$. (1 ft.) in the two profiles examined. The greatest inhibitory effect was found to correspond approximately with the zone in which the greatest concentration of roots was present.

Of the fungi tested for sensitivity to fungistasis by these soils, Aspergillus niger and Trichoderma viride represented the two species most commonly isolated from soil at Ibadan, either by the dilution plate or by Warcup's soilplate method (Warcup, 1950). The other fungi whose spores were inhibited were also frequently isolated from local soils, with the exception of the plant pathogen Ustilago zeae. The sensitivity of the brandspores of this fungus to soil fungistasis may be associated with the fact that under natural conditions they frequently reach the soil before germination.

The confirmation by the present work of the occurrence in tropical soils of material which inhibits the germination of fungal spores, considered together 
with reports of a similar phenomenon in geographically widely separated areas, strongly suggests that such material may be almost universally present in soils. There can be no doubt that the existence of inhibitory substances in soils, the effects of which are only overcome under specific conditions, must exert a profound effect on the biology of soil-inhabiting fungi.

The author wishes to thank the staff of the Commonwealth Mycological Institute for help with identification, Mr David Chimbo for technical assistance, Dr H. G. Thornton, For.Sec. R.S., for helpful criticism and Miss Mabel Dunkley for preparing the typescript. This work forms part of a thesis to be presented for the Ph.D. degree of the University of London.

\section{REFERENCES}

Brian, P. W., Hemming, H. G. \& McGowan, J. C. (1945). Origin of toxicity in Wareham Heath soil. Nature, Lond. 155, 637.

Chinn, S. H. F. (1953). A slide technique for the study of fungi and actinomycetes in soil with special reference to Helminthosporium sativum. Canad. J. Bot. 31, 718.

Dobbs, C. G. \& Hinson, W. H. (1953). A widespread fungistasis in the soil. Nature, Lond. 172, 197.

Greig-Smith, S. (1911). The bacteriotoxins and the agricere of soils. Zbl. Bakt.30,154.

Hessayon, D. G. (1953). Fungitoxins in the soil. II. Trichothecin, its production and inactivation in unsterilized soil. Soil. Sci. 75, 395.

JACKSON, R. M. (1957). Fungistasis as a factor in the rhizosphere phenomenon. Nature, Lond. 180, 96.

Jefferys, E. G. \& Hemming, H. G. (1953). Fungistasis in soils. Nature, Lond.172, 872.

Melin, E. (1946). Der Einfluss von Waldstreuextrakten auf das Wachstum von Bodenpilzen, mit besonderer Berücksichtigung der Wurzelpilze von Bäumen. Symb. bot. upsaliens, 8, 1.

NeIlson-Jones, W. (1941). Biological aspects of soil fertility. J. agric. Sci. 31, 379.

Newman, A. S. \& Norman, A. G. (1943). The activity of subsurface soil populations. Soil. Sci. 55, 377.

Park, D. (1955). Experimental studies on the ecology of fungi in soil. Trans. Brit. mycol. Soc. 38, 130.

Park, D. (1956). Effect of substrate on a microbial antagonism, with reference to soil conditions. Trans. Brit. mycol. Soc. 39, 239.

Pochon, J. \& Barjac, H. DE (1952). Action inhibitrice des extraits aqueux de tourbe sur la croissance des germes du sol. Ann. Inst. Pasteur, 83, 196.

Simmonds, P. M., Sallans, B. J. \& Ledingham, R. J. (1950). The occurrence of Helminthosporium sativum in relation to primary infections in common root-rot of wheat. Sci. Agric. 30, 407.

Stover, R. H. (1955). Flood fallowing for eradication of Fusarium oxysporum $\mathbf{f}$. cubense. III. Effect of oxygen on fungus survival. Soil. Sci. 80, 397.

WARCUP, J. H. (1950). The soil-plate method for isolation of fungi from soil. Nature, Lond. 166, 117.

Winter, A. G. (1940). Untersuchungen über den Einfluss biotischer Faktoren auf die Infektion des Weizens durch Ophiobolus graminis. Z. Pflkrankh. 50, 113.

Winter, A. G. (1955). Untersuchungen über Vorkommen und Bedeutung von antimikrobiellen und antiphytotischen Substanzen in natürlichen Böden. $\boldsymbol{Z}$. PflErnähr. Düng. 69, 224.

Witkamp, M. \& Starkey, R. L. (1956). Tests of some methods for detecting antibiotics in soil. Proc. Soil Sci. Soc. Amer. 20, 500. 